\title{
Molecular Epidemiology of Enteric Adenovirus Gastroenteritis in under-Five-Year-Old Children in Iran
}

\author{
Anahita Sanaei Dashti, ${ }^{1}$ Pedram Ghahremani, ${ }^{2}$ \\ Tayebeh Hashempoor, ${ }^{3}$ and Abdollah Karimi ${ }^{2}$ \\ ${ }^{1}$ Shiraz HIV/AIDS Research Center, Shiraz University of Medical Sciences, Shiraz 7193613311, Iran \\ ${ }^{2}$ Pediatric Infectious Diseases Research Center, Shahid Beheshti University of Medical Sciences, Tehran, Iran \\ ${ }^{3}$ Professor Alborzi Clinical Microbiology Research Center, Namazi Hospital, Shiraz University of Medical Sciences, \\ Shiraz 7193613311, Iran \\ Correspondence should be addressed to Anahita Sanaei Dashti; anahita_sam@yahoo.com
}

Received 8 August 2015; Revised 25 October 2015; Accepted 26 October 2015

Academic Editor: Greger Lindberg

Copyright (C) 2016 Anahita Sanaei Dashti et al. This is an open access article distributed under the Creative Commons Attribution License, which permits unrestricted use, distribution, and reproduction in any medium, provided the original work is properly cited.

\begin{abstract}
Background. Acute gastroenteritis is one of the major sources of morbidity and mortality among young children in developed and developing countries. The aim of this study was to determine the prevalence of human adenovirus- (HAdV-) 40 and HAdV-41 in children hospitalized with gastroenteritis in five different health centers of Iran. Methods. In a cross-sectional epidemiological study, we studied $2682 \mathrm{fecal}$ specimens that were collected from children under the age of 5 years in five educational and therapeutic pediatric centers in Iran from February 2012 to February 2013. Samples were tested for HAdV-40 and HAdV-41, using a specific pair of primers in polymerase chain reaction (PCR) method. Results. HAdV-40 and HAdV-41 were detected in 132 (5.18\%) of the patients with diarrhea. A significantly higher prevalence of HAdV-40 and HAdV-41 (58.3\%) was observed in children under 12 months of age, compared to other age groups. The male to female ratio was 1.7. Conclusion. The results of this study demonstrated that HAdV40 and HAdV-41 could be considered etiological agents for acute gastroenteritis among children in Iran. The PCR as a rapid test may increase the chance for a relatively mild course of the disease followed by a complete recovery and avoiding administration of unnecessary antibiotics.
\end{abstract}

\section{Introduction}

Acute gastroenteritis is a very common disease that causes a significant mortality in developing countries. Worldwide, gastroenteritis affects 3 to 5 million children each year [1] and accounts for 1.5 to 2.5 million deaths per year or $12 \%$ of all deaths among children less than 5 years of age [1-3].

Though it seldom causes death in developed countries, it puts a heavy burden on the health care system [4], as it accounts for $10 \%$ of all hospital admissions for children under the age of 5 years.

Viruses are the most important etiologic causes responsible for approximately $70 \%$ of the episodes of acute gastroenteritis in children [4]. Worldwide, rotavirus is still the most common virus causing this disease $[5,6]$, followed by adenovirus types 40 and 41 , astrovirus, and calicivirus $[6,7]$. The rate of enteric adenovirus 40 and 41 varies from $1-8 \%$ in developed countries to $2-31 \%$ in developing countries [5, 7], but the prevalence is increased in immunocompromised patients [8].

Human adenoviruses (HAdVs) are one of the major causes of a number of different clinical syndromes including gastroenteritis, respiratory disease, conjunctivitis, hemorrhagic cystitis, and exanthema. They comprise 51 different serotypes (HAdV-1 to HAdV-51) grouped into 6 species, A to $\mathrm{F}$. The enteric serotypes that are mostly associated with gastroenteritis are Ad-40 and Ad- 41 which belong to species F.

Enteric adenoviruses associated with protracted diarrhea which may contribute to infant dehydration and malnutrition in developing countries $[4,5]$ spread predominantly by the fecal-oral route $[3,4]$. Usually, after an incubation period of 8 to 10 days, periodic diarrhea occurs, with low grade fever, vomiting, abdominal pains, and dehydration $[3,6]$. 
In a survey done in Taiwan, clinical features of enteric adenoviruses types 40 and 41 in children were diarrhea (96.9\%), fever $(54.7 \%)$, vomiting $(45.3 \%)$, mild dehydration $(43.8 \%)$, symptoms of upper respiratory tract infection (21.9\%), and abdominal pain (12.5\%) [9]. Long-lasting diarrhea (mean 10.8 days) was a predominant symptom of enteric adenoviruses in comparison to rotavirus [10]. In another comparative study, adenovirus gastroenteritis differed from rota- and astrovirus infections by subacute onset, less frequent vomiting, more frequent development of mild and moderate dehydration, and abdominal pains and distension [11].

These viruses exist year-round in all parts of the world but are most prevalent during spring, early summer, and midwinter in temperate climates $[3,5]$.

The present study was performed to identify the predominant adenovirus serotypes and their epidemiologic characteristics in infants and children with acute gastroenteritis from five different pediatric therapy centers in Iran.

\section{Methods and Materials}

The study was carried out from February 2012 to February 2013 on 2682 stool samples, obtained within 48 hours of admission to the hospitals of children under 5 years, suffering from acute gastroenteritis, from five different cities of Iran: Tehran, Shiraz, Mashhad, Tabriz, and Bandar Abbas. All the patients were examined according to the criteria described earlier for the number of episodes and the duration of vomiting and diarrhea, associated symptoms, and the extent of dehydration and treatment [12]. Patients with acquired or congenital immune deficiency were excluded from the study. The fecal specimens were stored at $-70^{\circ} \mathrm{C}$ immediately for later virological tests. Informed consents were obtained from parents before collecting the samples. The Ethics Committee of Shahid Beheshti University of Medical Sciences approved the study. Demographic data were collected by questionnaires including sex, age, and living place. The specimens were stored at $-80^{\circ} \mathrm{C}$ until processing to detect viral antigens.

The viral nucleic acid was extracted from stool suspensions by using the Bioneer kit, according to the manufacturer's instructions (Bioneer, Korea).

The extracted DNA was used as a template for amplification of HAdV-hexon gene. A 261 bp fragment was amplified using specific sense and antisense primers (Ref) including 5GCCACCGATACGTACTTCAGCCTG-3 and 5-GGCAGTGCCGGAGTAGGGTTTAAA-3, respectively [13]. Briefly, the extracted DNA was amplified by standard PCR using primers recognizing the $\mathrm{HAdV}$-hexon region. The reaction mixture consisted of $0.2 \mathrm{mM}$ dNTP, $1.5 \mathrm{mM} \mathrm{MgCl} 2,1 \mathrm{U}$ of Taq DNA polymerase (Fermentas, Lithuania), PCR-buffer $1 \mathrm{x}$ (Fermentas, Lithuania), and $1 \mathrm{mM}$ of each primer. The PCR conditions consisted of 30 cycles of $4 \mathrm{~min}$ at $94^{\circ} \mathrm{C}, 30 \mathrm{~s}$ at $94^{\circ} \mathrm{C}, 62 \mathrm{~s}$ at $60^{\circ} \mathrm{C}, 60 \mathrm{~s}$ at $72^{\circ} \mathrm{C}$, and a final extension cycle of $72^{\circ} \mathrm{C}$ for $7 \mathrm{~min}$. PCR products were loaded on $1 \%$ agarose gel along with $100 \mathrm{bp}$ molecular size DNA ladder (Fermentas, Lithuania).

Descriptive analysis including frequencies and nonparametric tests including chi-square and $t$-test were performed.

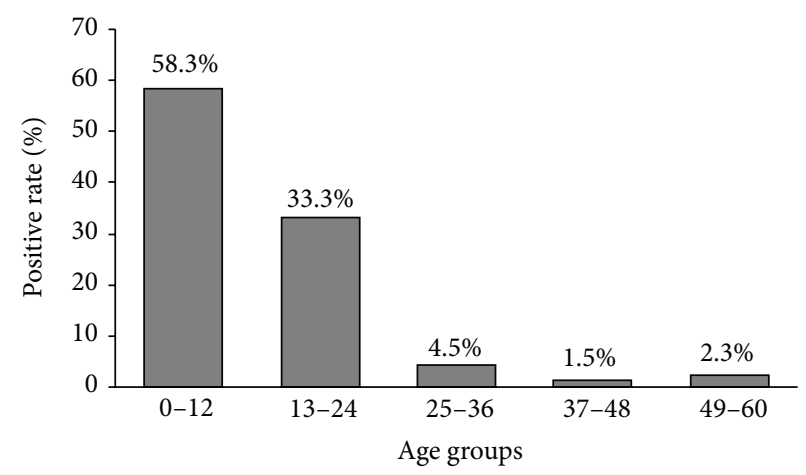

FIgURE 1: Age wise distribution of HAdV-40 and HAdV-41 positivity in gastroenteritis patients.

Comparison of the mean values between groups was performed using the $t$-test. A $P$ value of 0.05 or less was considered to be statistically significant. Data analysis was carried out using statistical software SPSS version 15 .

\section{Results}

A total of 132 out of 2982 (5.18\%) episodes of acute gastroenteritis were associated with Ad-40, Ad-41 genomic detection. The samples of healthy control were not positive.

The highest incidence of diarrhea caused by Ad-40 and Ad-41 was in children less than 24 months of age (121 cases or $91.6 \%$ ) and less than 12 months of age (77 cases or $58.3 \%$ ) and in children between 6 and 12 months of age (32 cases or $24.2 \%$ ) (Figure 1 ). The rate of infection was significantly different between children under 24 months of age and the older ones (Chi-Square, $P<0.0001$ ). Males and females constituted $62.87 \%$ and $37.1 \%$ of the patients with positive result, respectively. The male to female ratio was 1.7 .

\section{Discussion}

Viruses are the most common cause of diarrhea in children. After rotavirus, enteric adenovirus is assumed as an important cause of viral diarrhea leading to noticeable deaths in children in many countries [14]. Among different types of HA, adenoviruses types 40 and 41 are one of the most common etiological agents of acute gastroenteritis among infants and young children less than two years of age $[15,16]$.

Fodha et al. examined 638 stool samples to assess the incidence of diarrhea related viral pathogens in Tunisian children. According to the results, rotaviruses, astroviruses, and adenoviruses types $40 / 41$ were present in about $30 \%$ of specimen. The astroviruses had the highest incidence in diarrhea and the frequency of adenovirus strains was $6 \%$ in this study [17]. In a multicenter case-control study in Africa and south Asia on 9439 children, rotavirus and, to a lesser extent, adenovirus $40 / 41(<5 \%)$ were the most common pathogens causing moderate-to-severe diarrhea in children [18].

Moyo et al. found that the frequency of adenovirus infection was higher in under-1-year-old infants. Also, they 
reported that nondiarrheic and diarrheic children had similar prevalence of adenovirus [19].

The other viruses that are now recognized to play a major role in sporadic gastrointestinal illnesses are noroviruses [20]. Early serosurveys documented a high prevalence of norovirus antibodies in children, but, because the virus was rarely detected in fecal specimens, its role in causing the infection seemed questionable [21].

The present study highlights the prevalence of enteric adenoviruses, HAdV-40 and HAdV-41, among acute gastroenteritis cases from five different cities of Iran. Viral DNA was detected using PCR technique. HAdV-40 and HAdV-41 infection was found in $5.18 \%$ of children with diarrhea but was not detected in the control group.

There are different reports about the prevalence of viral gastroenteritis in Iran. Previous epidemiological studies in Iran such as those done by Shokrollahi, Motamedifar, and Hamkar showed that $20 \%, 9 \%$, and $2.3 \%$ of viral gastroenteritis were attributable to the adenoviruses, respectively [22-24]. However, a review of published data about viral gastroenteritis in Iran from 2002 to 2013 showed that enteric adenovirus incidence was $5.7 \%$ in children with acute gastroenteritis [25] which is consistent with our findings.

Also, a previous study conducted by Nakhaei Sistani et al. reported that $6.25 \%$ of Iranian children from neonates up to ten years old were positive for genomic HAdV-40 and HAdV$41[26]$.

In other countries, a low rate of adenovirus infection was reported. In countries like Turkey, the USA, Thailand, Korea, the UK, Australia, Argentina, Sweden, and France, the prevalence of enteric adenovirus ranged from 1.55 to $15 \%$, compared to that of our study, that is, $5.18 \%$ [27-32].

In an analysis of the age group with $\mathrm{HAdV}-40$ and $\mathrm{HAdV}$ 41 infections, we observed that $91.7 \%$ (121/132) of positive cases were children under 2 years of age. The age distribution was similar to that reported by previous study [9].

In this study, vomiting, fever, abdominal pains, watery diarrhea, and dehydration were the most common specific symptoms in children with HAdV-40 and HAdV-41 infections, similar to previously reported study [33].

To avoid false-positive serological results caused by past infection of HAdV-40 and HAdV-41, using the speciesspecific PCR that is an available tool for the characterization of HAdV-40 and HAdV-41 with the advantage of testing clinical specimens directly is highly recommended.

There are some difficulties in establishing the diagnosis of HAdV-40 and HAdV-41 infections including the lack of a rapid and sensitive diagnostic method for use in public health laboratories and hospitals; consequently, the frequency of these viral infections is underestimated.

The main methods used to detect HAdVs in clinical samples such as blood and stools are antigen detection assays, such as enzyme-linked-immunosorbent assay (ELISA), immunofluorescence (IF) or immunochromatography tests, or PCR-based techniques. All immune-detection methods are of particular interest because they yield results quickly; besides, these methods are generally used for screening HAdVs in stool samples or respiratory fluids, since these kinds of samples are heavily loaded with HAdV particles, in case of infection [34, 35].

However, although the PCR test for diagnosis of these viral infections, HAdV-40 and HAdV-41, is the gold standard, it is not routinely performed on all stool specimens negative for bacterial and other viral infections including rotavirus, despite the fact that HAdV-40 and HAdV-41 are almost a common cause of infectious gastroenteritis.

Given such conditions, acute diarrhea remains a major public health problem in developing countries including Iran, and the detection of the HAdV-40 and HAdV-41 infections could improve the diagnostic coverage of viral gastroenteritis in children $<2$ years of age, the major age group affected by this disease $[15,16]$.

\section{Conclusion}

Admitting the diarrhea as an important cause of mortality and morbidity in children worldwide and understanding the prevalence of pathogens involved in diarrhea are a key strategy for prevention policies and antibiotic stewardship programs. The present study showed that a small proportion of cases (5\%) were attributable to adenoviruses types 40 and 41 , a fact that would be leading in the above-mentioned issues.

\section{Abbreviations}

HAdV: Human adenovirus

PCR: Polymerase chain reaction.

\section{Conflict of Interests}

The authors declare that they have no conflict of interests.

\section{Authors' Contribution}

Anahita Sanaei Dashti performed design of study and contributed in paper drafting. Pedram Ghahremani performed data acquisition follow-up and assisted in data analysis. Tayebeh Hashempoor contributed in drafting the paper. Abdollah Karimi participated in the design of study.

\section{Acknowledgments}

This work was financially supported by Shahid Beheshti University of Medical Sciences, Tehran, Iran. The authors also express special thanks to Mr. Javad Moayedi at Professor Alborzi Clinical Microbiology Research Center, Namazi Hospital, Shiraz University of Medical Sciences, Shiraz, Iran, for statistical assistance. Their thanks also go to Hassan Khajehei, Ph.D., for copyediting of the paper.

\section{References}

[1] J. Dalby-Payne and E. Elliott, "Gastroenteritis in children," Clinical Evidence, vol. 12, pp. 443-454, 2004.

[2] Centers for Disease Control and Prevention, "Managing acute gastroenteritis among children: oral rehydration, maintenance, and nutritional therapy," Pediatrics, vol. 114, no. 2, p. 507, 2004. 
[3] M. Santosham, "Oral rehydration therapy: reverse transfer of technology," Archives of Pediatrics \& Adolescent Medicine, vol. 156, no. 12, pp. 1177-1179, 2002.

[4] C. M. Chow, A. K. C. Leung, and K. L. Hon, "Acute gastroenteritis: from guidelines to real life," Clinical and Experimental Gastroenterology, vol. 3, no. 1, pp. 97-112, 2010.

[5] O. Djeneba, K. Damintoti, I. Denise et al., "Prevalence of rotavirus, adenovirus and enteric parasites among pediatric patients attending Saint Camille Medical Centre in Ouagadougou," Pakistan Journal of Biological Sciences, vol. 10, no. 23, pp. 4266-4270, 2007.

[6] I. Wilhelmi, E. Roman, and A. Sánchez-Fauquier, "Viruses causing gastroenteritis," Clinical Microbiology and Infection, vol. 9, no. 4, pp. 247-262, 2003.

[7] M. M. Meqdam and I. R. Thwiny, "Prevalence of group a rotavirus, enteric adenovirus, norovirus and astrovirus infections among children with acute gastroenteritis in Al-Qassim, Saudi Arabia," Pakistan Journal of Medical Sciences, vol. 23, no. 4, pp. 551-555, 2007.

[8] A. M. Leen and C. M. Rooney, "Adenovirus as an emerging pathogen in immunocompromised patients," British Journal of Haematology, vol. 128, no. 2, pp. 135-144, 2005.

[9] H.-C. Lin, C.-L. Kao, C.-Y. Lu et al., "Enteric adenovirus infection in children in Taipei," Journal of Microbiology, Immunology, and Infection, vol. 33, no. 3, pp. 176-180, 2000.

[10] I. Uhnoo, E. Olding-Stenkvist, and A. Kreuger, "Clinical features of acute gastroenteritis associated with rotavirus, enteric adenoviruses, and bacteria," Archives of Disease in Childhood, vol. 61, no. 8, pp. 732-738, 1986.

[11] M. Asilova, "Clinical characteristic of viral diarrhea in Uzbekistan," Medical and Health Science Journal, vol. 11, no. 2, pp. 7884, 2012.

[12] T. Ruuska and T. Vesikari, "Rotavirus disease in Finnish children: use of numerical scores for clinical severity of diarrhoeal episodes," Scandinavian Journal of Infectious Diseases, vol. 22, no. 3, pp. 259-267, 1990.

[13] J. Rohayem, S. Berger, T. Juretzek et al., "A simple and rapid single-step multiplex RT-PCR to detect Norovirus, Astrovirus and Adenovirus in clinical stool samples," Journal of Virological Methods, vol. 118, no. 1, pp. 49-59, 2004.

[14] A. Shetty, F. Kalekhan, S. Muthiravalapil, R. Boloor, and B. Antony, "Detection of Rotavirus and Adenovirus diarrhea in children below five years, in Dakshina Kannada District, a coastal region of Karnataka State, India," Muller Journal of Medical Sciences and Research, vol. 5, no. 2, p. 143, 2014.

[15] K. Jarecki-Khan, S. R. Tzipori, and L. E. Unicomb, "Enteric adenovirus infection among infants with diarrhea in rural Bangladesh," Journal of Clinical Microbiology, vol. 31, no. 3, pp. 484-489, 1993.

[16] N. R. Blacklow and H. B. Greenberg, "Viral gastroenteritis," The New England Journal of Medicine, vol. 325, no. 4, pp. 252-264, 1991.

[17] I. Fodha, A. Chouikha, I. Peenze et al., "Identification of viral agents causing diarrhea among children in the Eastern Center of Tunisia," Journal of Medical Virology, vol. 78, no. 9, pp. 11981203, 2006.

[18] K. L. Kotloff, J. P. Nataro, W. C. Blackwelder et al., "Burden and aetiology of diarrhoeal disease in infants and young children in developing countries (the Global Enteric Multicenter Study, GEMS): a prospective, case-control study," The Lancet, vol. 382, no. 9888 , pp. 209-222, 2013.
[19] S. J. Moyo, K. Hanevik, B. Blomberg et al., "Prevalence and molecular characterisation of human adenovirus in diarrhoeic children in Tanzania; a case control study," BMC Infectious Diseases, vol. 14, no. 1, article 666, 2014.

[20] X.-L. Pang, J. Joensuu, and T. Vesikari, "Human calicivirusassociated sporadic gastroenteritis in Finnish children less than two years of age followed prospectively during a rotavirus vaccine trial," The Pediatric Infectious Disease Journal, vol. 18, no. 5, pp. 420-426, 1999.

[21] R. I. Glass, U. D. Parashar, and M. K. Estes, "Norovirus gastroenteritis," The New England Journal of Medicine, vol. 361, no. 18, pp. 1726-1785, 2009.

[22] M. R. Shokrollahi, S. Noorbakhsh, H. R. Monavari, S. G. Darestani, A. V. Motlagh, and S. J. Nia, "Acute nonbacterial gastroenteritis in hospitalized children: a cross sectional study," Jundishapur Journal of Microbiology, vol. 7, no. 12, Article ID e11840, 2014.

[23] M. Motamedifar, E. Amini, and P. T. Shirazi, "Frequency of rotavirus and adenovirus gastroenteritis among children in Shiraz, Iran," Iranian Red Crescent Medical Journal, vol. 15, no. 8, pp. 729-733, 2013.

[24] R. Hamkar, Y. Yahyapour, M. Noroozi et al., "Prevalence of rotavirus, adenovirus, and astrovirus infections among patients with acute gastroenteritis in, Northern Iran," Iranian Journal of Public Health, vol. 39, no. 2, pp. 45-51, 2010.

[25] Z. Shoja, S. Jalilvand, Y. Mollaei-Kandelous, and M. Validi, "Epidemiology of viral gastroenteritis in Iran," The Pediatric Infectious Disease Journal, vol. 33, no. 2, pp. 218-220, 2014.

[26] R. N. Sistani, M. Sadeghizadeh, H. Saderi, N. K. Tafreshi, M. Behmanesh, and H. Shirzad, "Detection of types 40 and 41 adenoviruses in stool samples of diarrheal children by solid phase PCR," Iranian Journal of Biotechnology, vol. 5, no. 1, 2007.

[27] K.-H. Kim, J.-M. Yang, S.-I. Joo, Y.-G. Cho, R. I. Glass, and Y.-J. Cho, "Importance of rotavirus and adenovirus types 40 and 41 in acute gastroenteritis in Korean children," Journal of Clinical Microbiology, vol. 28, no. 10, pp. 2279-2284, 1990.

[28] G. L. Barnes, E. Uren, K. B. Stevens, and R. F. Bishop, "Etiology of acute gastroenteritis in hospitalized children in Melbourne, Australia, from April 1980 to March 1993," Journal of Clinical Microbiology, vol. 36, no. 1, pp. 133-138, 1998.

[29] F. Bon, P. Fascia, M. Dauvergne et al., "Prevalence of group A rotavirus, human calicivirus, astrovirus, and adenovirus type 40 and 41 infections among children with acute gastroenteritis in Dijon, France," Journal of Clinical Microbiology, vol. 37, no. 9, pp. 3055-3058, 1999.

[30] A. Bereciartu, K. Bok, and J. Gómez, "Identification of viral agents causing gastroenteritis among children in Buenos Aires, Argentina," Journal of Clinical Virology, vol. 25, no. 2, pp. 197203, 2002.

[31] K.-T. Chen, P.-Y. Chen, R.-B. Tang et al., "Sentinel hospital surveillance for rotavirus diarrhea in Taiwan, 2001-2003," Journal of Infectious Diseases, vol. 192, supplement 1, pp. S44-S48, 2005.

[32] L. Vernacchio, R. M. Vezina, A. A. Mitchell, S. M. Lesko, A. G. Plaut, and D. W. K. Acheson, "Diarrhea in American infants and young children in the community setting: incidence, clinical presentation and microbiology," Pediatric Infectious Disease Journal, vol. 25, no. 1, pp. 2-7, 2006.

[33] S. A. Acra and F. K. Ghishan, "Electrolyte fluxes in the gut and oral rehydration solutions," Pediatric Clinics of North America, vol. 43, no. 2, pp. 433-449, 1996. 
[34] S. Bonot, L. Ogorzaly, B. El Moualij, W. Zorzi, and H.-M. Cauchie, "Detection of small amounts of human adenoviruses in stools: comparison of a new immuno real-time PCR assay with classical tools," Clinical Microbiology and Infection, vol. 20, no. 12, pp. O1010-O1016, 2014.

[35] S. Matthes-Martin, T. Feuchtinger, P. J. Shaw et al., "European guidelines for diagnosis and treatment of adenovirus infection in leukemia and stem cell transplantation: summary of ECIL-4 (2011)," Transplant Infectious Disease, vol. 14, no. 6, pp. 555-563, 2012. 


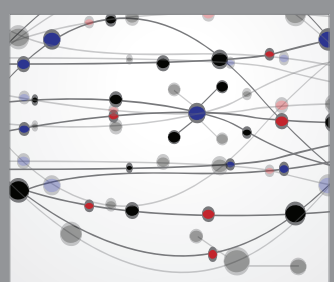

The Scientific World Journal
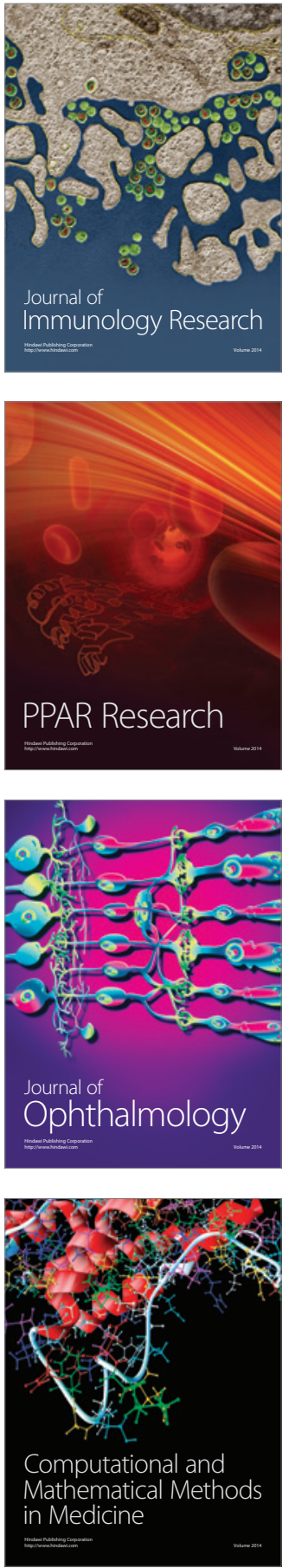

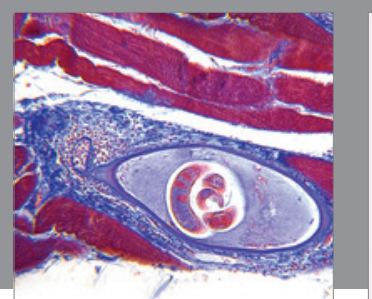

Gastroenterology Research and Practice

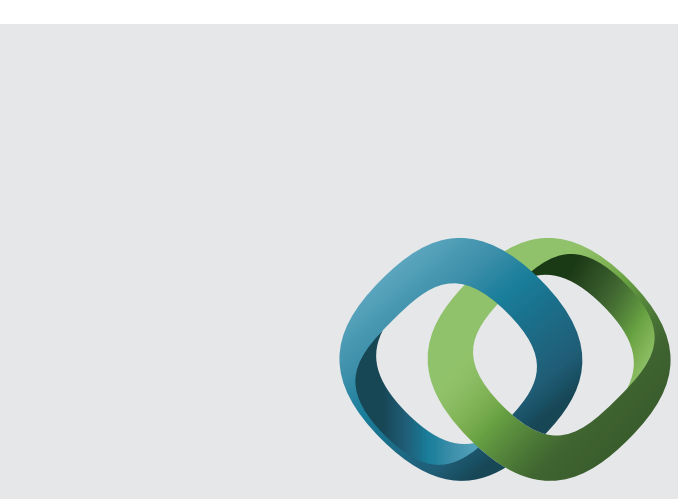

\section{Hindawi}

Submit your manuscripts at

http://www.hindawi.com
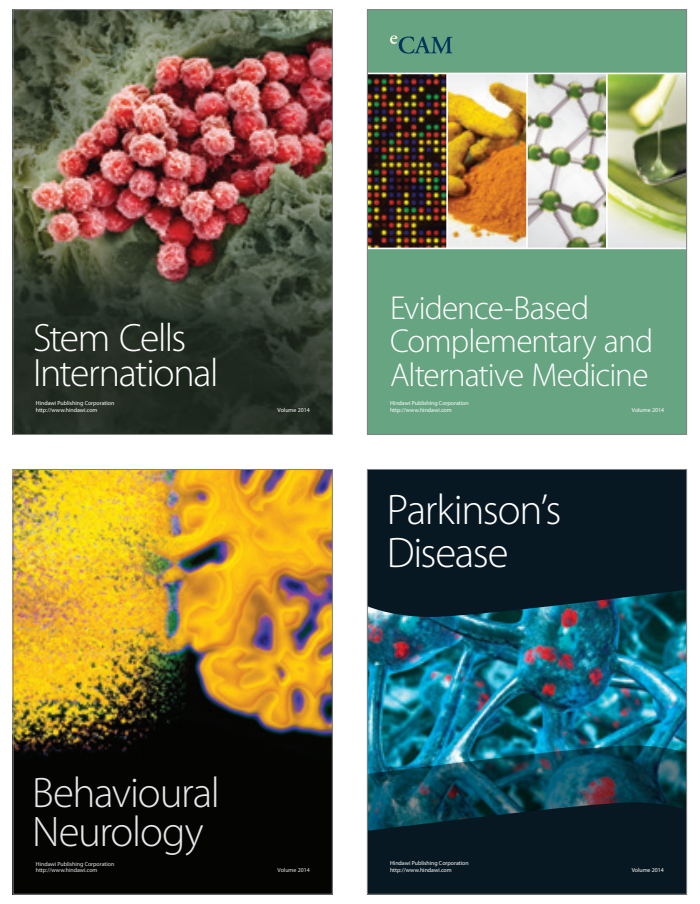
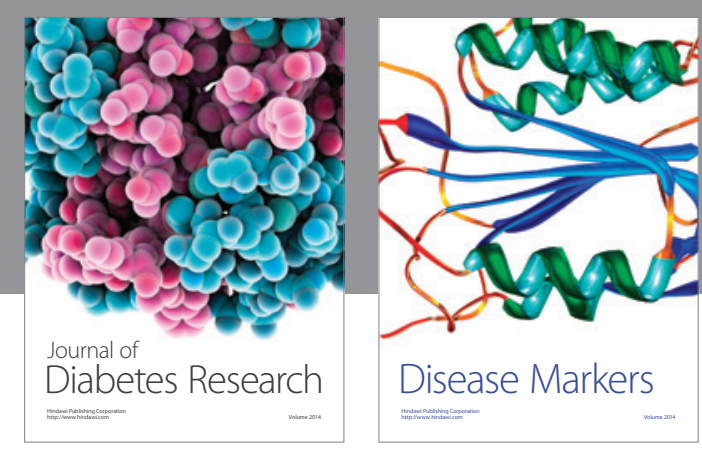

Disease Markers
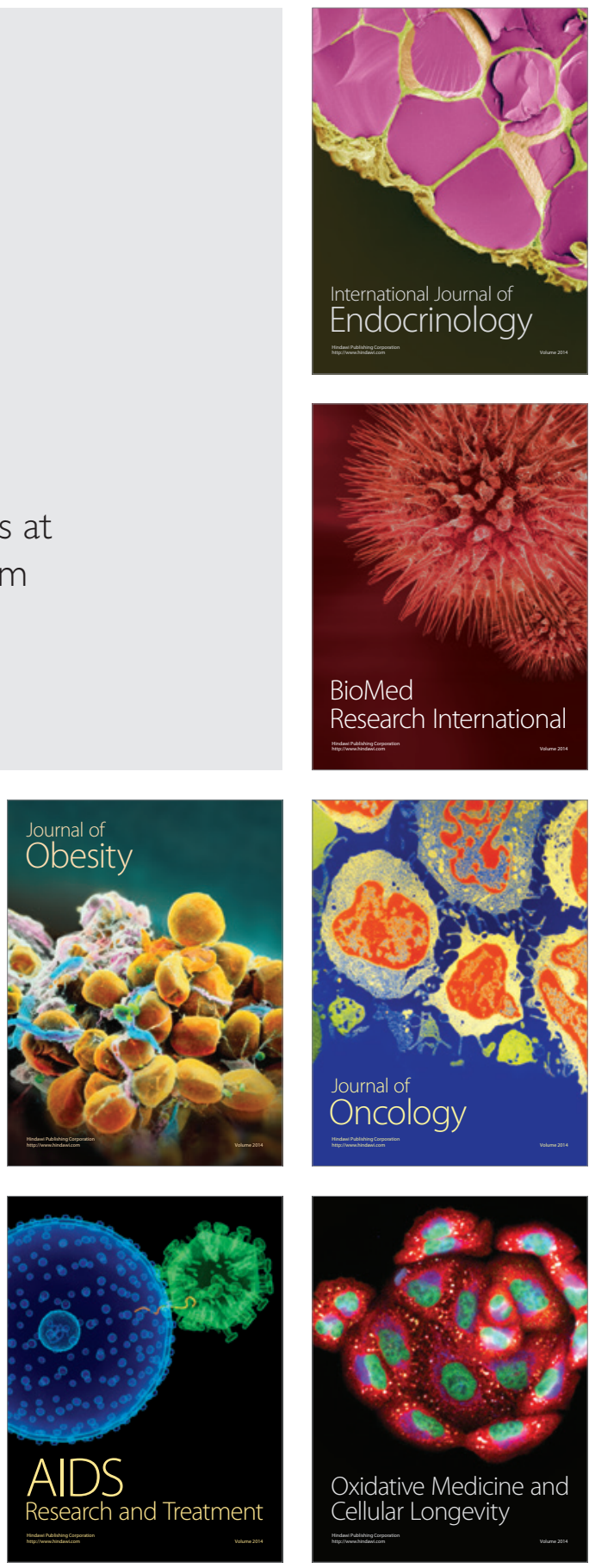